\title{
Learning efficiency: The influence of cue salience during spatial navigation
}

\author{
Francesca R. Farina, Teresa Burke, Darragh Coyle, Kirby Jeter, Michelle McGee, \\ Jennifer O'Connell, Darragh Taheny, Sean Commins*
}

Department of Psychology, Maynooth University, Maynooth, Co. Kildare, Ireland

\section{A R T I C L E I N F O}

\section{Article history:}

Received 12 February 2015

Received in revised form 23 April 2015

Accepted 23 April 2015

Available online 25 April 2015

\section{Keywords:}

Rats

Navigation

Water maze

Cue salience

Learning strategy

Training length

\begin{abstract}
A B S T R A C T
In three experiments, male Wistar rats were trained to find a hidden platform in the Morris water maze using two cues for five or ten days. Experiments 1 and 2 investigated two factors of cue salience; proximity to the goal and brightness. Results from Experiment 1 showed that rats tested with a bright distal cue were significantly better at locating the platform than rats tested with the proximal cue after five- and ten-day training with both cues. In Experiment 2, the position of the cues was reversed. Rats tested with a brighter proximal cue outperformed those tested with a distal cue. Findings from Experiments 1 and 2 suggest that brightness acquired more control over rats' behaviour than proximity to the goal. Animals in Experiment 3 were trained with equally bright proximal and distal cues. Unexpectedly, probe tests revealed that rats tested with the farther cue were more accurate than those tested with the proximal cue, but only after extended training. Possible explanations for this result are discussed with reference to errors in directional information estimation and cue assignment, cue elevation and the use of the pool wall as a navigational aid. Taken together, findings point towards the use of an elemental learning strategy involving the more salient of the two cues which emerged earlier when the relative saliences of the cues differed considerably.
\end{abstract}

(c) 2015 Elsevier B.V. All rights reserved.

\section{Introduction}

The importance of environmental cues for successful navigation is well-documented in many species (for reviews see Rodrigo, 2002; Tommasi et al., 2012). According to associative theories of spatial learning, navigating animals form representations of cues from a collection of viewpoints, which then become associated with a goal destination (Hamilton et al., 2002; Honey et al., 2014; Leonard and McNaughton, 1990). These associations are thought to be created in one of two ways; elementally or configurally (Siegel and White, 1975; Sutherland and Rudy, 1989). Elemental learning strategies (e.g. Miller and Shettleworth, 2007; Rescorla and Wagner, 1972) occur where the animal forms direct associations between each cue and the destination separately (Pearce, 2002). When navigating to the goal, the animal must therefore identify the cues and remember their discrete spatial relationships to that location. Configural learning strategies (e.g. Rescorla et al., 1985; Rudy and Sutherland, 1995) involve the association of a cue configuration with the destination, where a novel configural representation (independent

\footnotetext{
* Corresponding author. Tel.: +353 1 7086182; fax: +3531 7084767.

E-mail address: Sean.Commins@nuim.ie (S.Commins).
}

of the individual cue components) is generated (Honey et al., 2014; Pearce, 2002). Here, the animal is required to remember the position of the goal relative to the complete configuration.

Research in various species has attempted to discriminate between configural and elemental strategies by altering the arrangement of cues between navigational training and testing phases. Using this approach, evidence for elemental strategy use has been found in children and non-human primates (MacDonald et al., 2004), gerbils (Collett et al., 1986) and pigeons (Spetch et al., 1996). Specifically, results illustrated that, when trained to locate a goal in the centre of a fixed array of cues and tested with the distance between these cues increased, animals tended to search for the goal at the absolute distance and direction from individual cues rather than at the relative midpoint of the configuration. Moreover, Collett et al. (1986) showed that when one of the two trained cues was removed, gerbils searched in two distinct locations which corresponded to the distances and directions from each cue to the goal during training. On the other hand, adult humans (Spetch et al., 1996; Spetch et al., 1997) and honeybees (Cartwright and Collett, 1982) have been known to search in the same relative location during testing as in training; for example, if trained to navigate to the centre of a cue arrangement, they continue to search in the centre of the expanded array, suggesting a configural strategy. More 
interestingly, the use of both strategies has been documented in Clark's Nutcracker birds (Kamil and Jones, 1997, 2000), indicating that configural and elemental learning may not be mutually exclusive. Rather, the use of a particular strategy may be influenced by the nature of the cues available to the animal in a given scenario.

Cue salience arguably plays a vital role in determining the type of learning strategy an animal will use, although it has not yet been studied to any great extent in the spatial domain (Rodrigo et al., 2014). The term salience can be defined as the "significance or noticeability" of a cue (Chamizo et al., 2006c, p. 340). There are a number of factors which can influence cue salience (Domjan et al., 2010). One such well-established factor is the distance of a cue from the goal location, whereby proximal cues acquire more control over navigation (i.e. become more salient) than distal cues (Artigas et al., 2005; Chamizo, 2002; Chamizo and Rodrigo, 2004; Cheng et al., 1987; Redhead and Hamilton, 2007; Spetch and Wilkie, 1994). This effect is thought to occur because proximal cues offer the most precise spatial information about the location of the goal (Spetch, 1995). That is, estimates of the distance and direction in which to travel are more variable for distant cues and, thus, more prone to error (Kamil and Cheng, 2001; Spetch, 1995). Specific features of a cue (e.g. size or luminance) have also been shown to effect salience (Chamizo et al., 2006c, 2012; Young et al., 2006). Chamizo et al. (2006c), for example, demonstrated that rats navigating in the Morris water maze with a bright distal cue performed as well as those navigating with a less luminous proximal cue.

Recently, Rodrigo et al. (2014) examined the effects of varying the salience of a cue configuration on the type of strategy employed by rats in the Morris water maze. Cues ranged from having approximately the same salience to having different saliences across conditions. Probe trials revealed that rats could adopt different spatial strategies, depending on the similarity of the cues' saliences (Rodrigo et al., 2014). Namely, when the salience was comparable, rats relied on the arrangement of cues (i.e. a configural strategy), and when salience was dissimilar, they used an elemental strategy involving the more salient of the two cues to reach the platform (Rodrigo et al., 2014). Notably, Rodrigo et al. (2014) suggest that the emergence of these distinct strategies may be somewhat dependant on a prolonged training period. Although this idea has not yet been thoroughly examined in a spatial learning context, visual discrimination research in honeybees has demonstrated that extended training can in fact produce a change in the chosen strategy, from elemental to configural (Giurfa et al., 2003).
Giurfa et al. (2003) also showed that, at longer training lengths, perceptual similarity between cues promoted a configural learning approach.

The current study aimed to expand on previous work in two ways; firstly, by further exploring the effects of altering cue salience on spatial learning strategies used in the Morris water maze, and secondly, by delineating the influence of training length on the type of strategy used. Experiment 1 examined two components of cue salience; distance from the goal and brightness. Rats were trained with a proximal (near) cue and a bright distal (far) cue for five or ten days and subsequently tested with both or one of these cues. We hypothesised that if one cue acquired more salience than the other, rats would initially adopt an elemental strategy with the high salience cue; however, if both cues became equally salient, rats should readily incorporate both into a configural strategy after only five days of training. Experiments 2 and 3 examined animals' learning behaviour in the presence of two cues with more distinct saliences. In Experiment 2, rats were trained with the original positions of the cues reversed. Here, as one cue was both brighter and closer to the goal, we expected rats to employ an elemental strategy with this cue. In Experiment 3, rats were trained with equally bright near and far cues. We predicted that rats would favour an elemental strategy involving the proximal cue to begin with, but after further training, may incorporate the farther cue into a configural strategy (similar to Giurfa et al., 2003).

\section{Experiment 1}

Experiment 1 had three aims; firstly to establish which component of cue salience (proximity or brightness), if any, acquired more control over navigation, secondly to identify if rats were using an elemental or configural learning strategy, and thirdly to determine if increased training could lead to a change in strategy. Rats were trained in the hidden platform version of the water maze (Morris, 1981 ) for five or ten days with a near cue and a brighter far cue, followed by testing with two cues or one cue.

\subsection{Method}

\subsubsection{Subjects and housing}

Subjects were 39 male Wistar rats (three months old at the beginning of training, 250-300 g) obtained from Charles River, UK. All rats were given a number with a non-toxic marker pen for

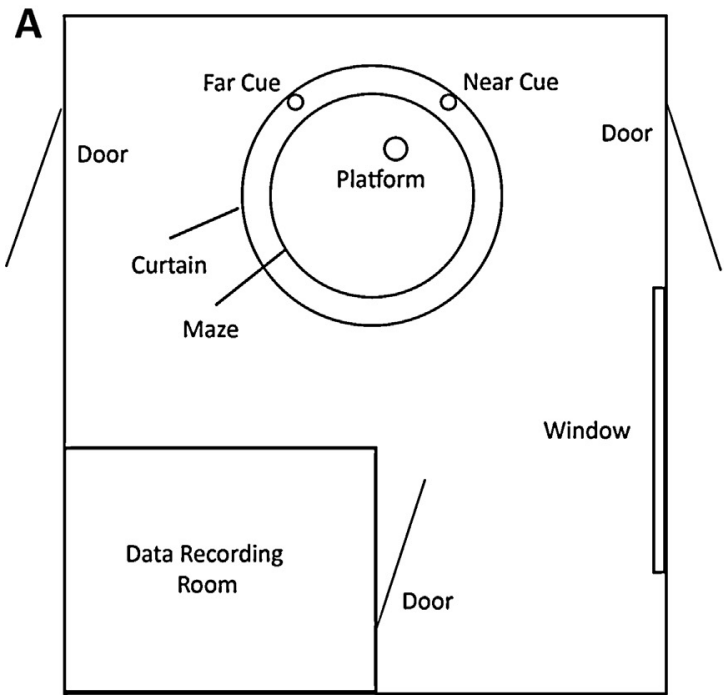

B

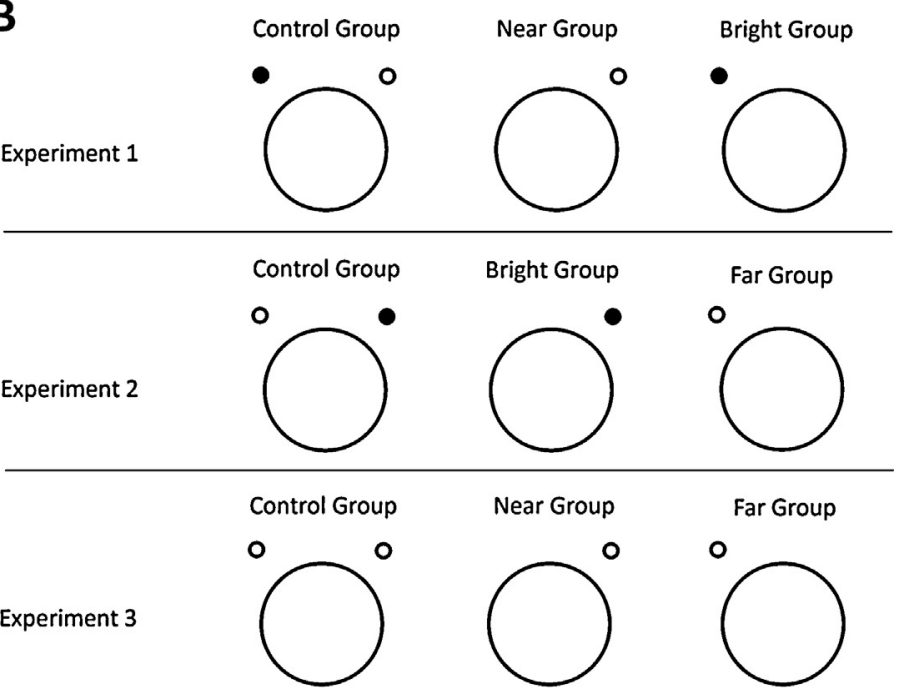

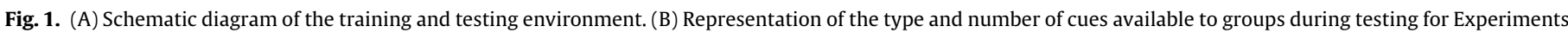
1-3. Open circles denote the $25 \mathrm{~W}$ light bulb and closed circles denote the brighter $40 \mathrm{~W}$ light bulb. 
identification purposes. Rats were housed three per cage in plasticbottomed cages $(56 \times 38 \mathrm{~cm}$ and $22 \mathrm{~cm}$ high; NKP Cages, UK) with a $3 \mathrm{~cm}$ layer of woodchip bedding, paper strip nesting material and cardboard tubes. All cages were cleaned out once a week. All rats had access ad libitum to water and food pellets and were maintained under a 12:12 h light:dark cycle (lights on at 07:00 h) at a fixed temperature of $21^{\circ} \mathrm{C}$. All rats were well handled for one week prior to the onset of training. Guidelines for the maintenance and experimentation of animals throughout this study conformed to the Department of Health and Children (Ireland) guidelines under statutory instrument (S.I.) No. 543 of 2012 and the European directive $2010 / 63 / \mathrm{EU}$

\subsubsection{Morris water maze apparatus}

The water maze consisted of a black, circular fibreglass pool ( $170 \mathrm{~cm}$ diameter, $35 \mathrm{~cm}$ deep) resting $70 \mathrm{~cm}$ above floor level on a metal support frame. The pool was filled with opaque water to a depth of $20 \mathrm{~cm}$ and maintained at $21 \pm 1^{\circ} \mathrm{C}$. A black concrete escape platform ( $13 \mathrm{~cm}$ diameter, $13.5 \mathrm{~cm}$ width) was placed in the centre of the northeast quadrant of the pool, $2 \mathrm{~cm}$ below the water surface and $25 \mathrm{~cm}$ from the edge of the pool wall. The maze was surrounded by a black curtain suspended from ceiling to floor at a distance of $60 \mathrm{~cm}$ from the pool wall which prevented access to room cues (see Fig. 1A for a schematic diagram of the testing room). The cues used in this study were two fluorescent, inside-frosted, low energy Philips glass light bulbs which were suspended from the ceiling directly inside the curtain. Cues were positioned northeast (NE; distance of $127 \mathrm{~cm}$, height angle of $42^{\circ}$; near cue) and northwest (NW; distance of $162 \mathrm{~cm}$, height angle of $25^{\circ}$; far cue) of the platform, respectively (see Fig. 1A). One $25 \mathrm{~W}$ light bulb (190 lumen light output; near cue) and one $40 \mathrm{~W}$ light bulb (370 lumen light output; bright cue) were used. For all experiments all rats were trained and tested in complete darkness (i.e. the two light bulbs were the only light source) to ensure that they learned to navigate using the distal cues. To minimise distraction for the animals (e.g. noise), all trials were observed by the experimenter in an adjacent testing room via a video camera positioned directly above the centre of the maze. Behavioural data were recorded using EthVision ${ }^{\odot}$ tracking system (Noldus Information Technologies, Wageningen, Netherlands).

\subsection{Morris water maze procedure}

\subsubsection{Acquisition}

Training for all rats consisted of four trials per day in the presence of both cues. Rats were trained for five $(n=21)$ or ten days $(n=18)$, totalling 20 or 40 trials. All training was completed between 09:00 and 12:00 h. For each trial, the rat was placed into the pool near to and facing the pool wall from one of four directional starting positions (north, south, east or west; see Fig. $1 \mathrm{~A}$ ) in a pseudo-randomised order. The time taken to reach the platform was recorded. If a rat failed to find the platform within $60 \mathrm{~s}$, they were guided there by the experimenter. Once on the platform, the rat remained there for $15 \mathrm{~s}$ before being placed in an open-topped box outside of the curtain for an inter-trial interval of $5 \mathrm{~s}$. Following this interval, the rat was placed back into the maze for the next trial. On completion of four trials, the rat was returned to their home cage.

\subsubsection{Retention}

Twenty-four hours after the final day of training (i.e. day 6 or day 11) rats were tested in a single $60 \mathrm{~s}$ probe trial with the platform removed. All retention trials were carried out between 09:00 and 12:00 h. Prior to the probe trial, rats were randomly divided into sub-groups. Rats trained for five days were separated into three groups; a Control group, Near group and Bright group ( $n=7$ per group). Rats trained for ten days were also divided into a Control group, Near group and Bright group ( $n=6$ per group). Rats in the Control groups were tested with both the near (NE) and bright (NW) cues present, as per training (see Fig. 1B, first row). Rats in the Near groups were tested with the near (NE) cue only, and those in the Bright groups were tested with the bright (NW) cue only (see Fig. 1B, first row). For groups tested with a single cue, the alternate cue was removed from view (the light was switched off and moved outside of the curtain). During the probe trial, all rats were placed into the pool near to and facing the centre of the SW quadrant (due to its novelty and its position opposite to the platform). Rats were allowed to swim freely for $60 \mathrm{~s}$. After the $60 \mathrm{~s}$ had elapsed, rats were returned to their home cages. To examine searching behaviour during the probe test, mean percentage time (of $60 \mathrm{~s}$ ) spent in the four quadrants of the maze and in four corresponding platform areas was recorded. Platform areas were defined as the circular areas surrounding the NE platform location and equivalent areas in the other three quadrants (NW, SE and SW; all $18 \mathrm{~cm}$ diameter). These areas were included in the analyses as a more refined measure of rats' searching behaviour during the probe trial (Hoz et al., 2004).

\subsection{Results}

\subsubsection{Acquisition}

Time taken to escape the maze was examined as a measure of task acquisition using mixed factorial analysis of variance (ANOVA) with group as the between-groups factor (Control, Near and Bright) and training day as the within-groups factor (days 1-5 or days 1-10). Tukey and Bonferroni post hoc tests were carried out, wherever they were appropriate. Rats were separated into their respective retention groups for escape latency analyses to ensure that they did not differ behaviourally during the training phase. ANOVAs revealed significant main effects of day after both five, $F_{4,72}=33.10, P=0.0001$, partial eta ${ }^{2}=0.65$, and ten days of training, $F_{9,135}=23.84, P=0.0001$, partial eta ${ }^{2}=0.61$. Bonferroni post hoc tests showed that rats trained for five days were significantly faster at finding the platform on day $5(14.36 \pm 1.49 \mathrm{~s} ; 95 \%$ CI [11.22, $17.48])$ compared to day $1(38.49 \pm 1.92 \mathrm{~s}, \mathrm{CI}[34.45,42.52] P=0.001$; see Fig. 2A). Similarly, rats trained for ten days escaped significantly faster on day $10(10.48 \pm 1.20 \mathrm{~s}, \mathrm{CI}[9.73,13.03])$ than on day 1 $(38.03 \pm 2.99, \mathrm{CI}[31.66,44.41], P=0.001$; see Fig. $2 \mathrm{~B})$. No significant group $\times$ day interaction effects were found.

The main effect of group was significant for rats trained for five days, $F_{1,18}=4.77, P=0.05$, partial eta ${ }^{2}=0.35$. Tukey post hoc tests showed an overall significant difference between the Control group and the Near group $(P=0.02)$. Between-groups, ANOVAs were then carried out to determine on which days these groups differed. Although no main effects were found, the observed post hoc difference appeared to be driven by escape patterns on days $1, F_{2,20}=3.08, P=0.07$, and 2 of training, $F_{2,20}=3.09, P=0.06$, which neared significance. Main effects on day $3: F_{2,20}=1.03, P=0.38$, day 4: $F_{2,20}=1.85, P=0.19$, and day $5: F_{2,20}=0.40, P=0.67$, were not significant. The main effect of group after ten days of training was not significant and no group differences were found on day ten.

\subsubsection{Retention}

To establish whether rats showed a significant preference for any quadrant during the probe test, percentage time spent in each quadrant was compared to chance level (25\%) for all groups using a series of one sample $t$-tests. As shown in Fig. $2 \mathrm{C}$, both Control and Bright groups trained for five days spent significantly longer in the target (NE) quadrant than expected by chance, $t_{12}=5.84$, $P=0.001$, and $t_{12}=2.70, P=0.04$, respectively, and significantly less time in the NW quadrant, $t_{12}=7.25, P=0.001$, and $t_{12}=4.37, P=0.01$, respectively. The Bright group also spent significantly more time in the $S E$ quadrant compared to chance, $t_{12}=4.52, P=0.01$. In contrast 
A

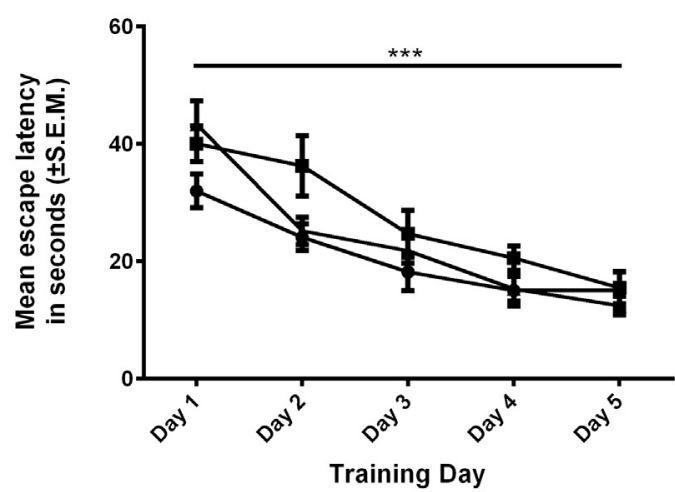

C

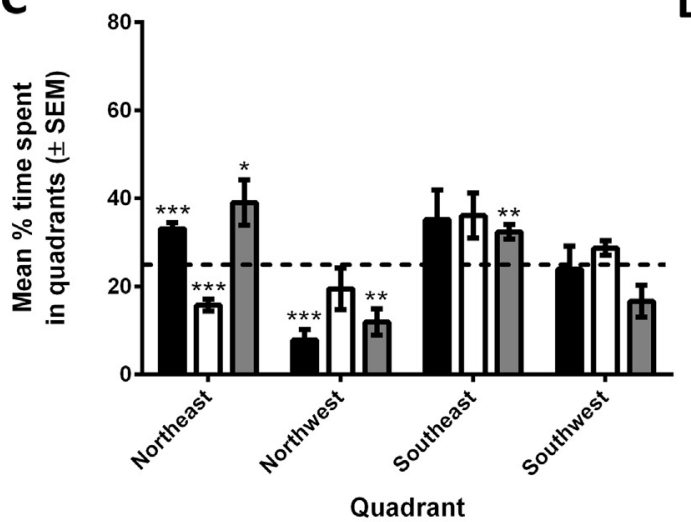

E

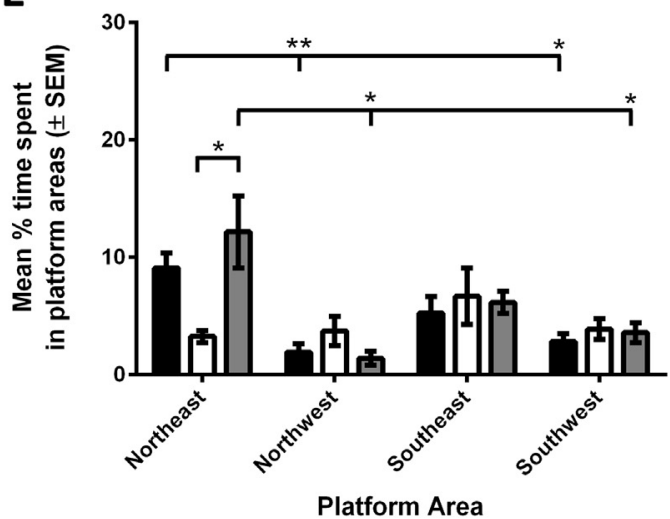

G 5 Day Training

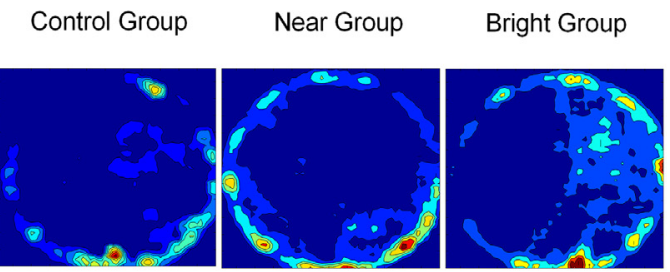

B 10 Day Training

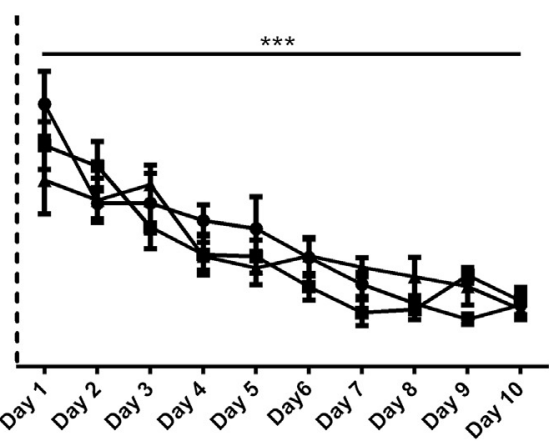

- Control Group

- Near Group

- Bright Group

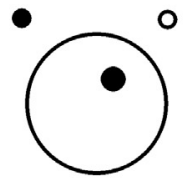

Training Day

D
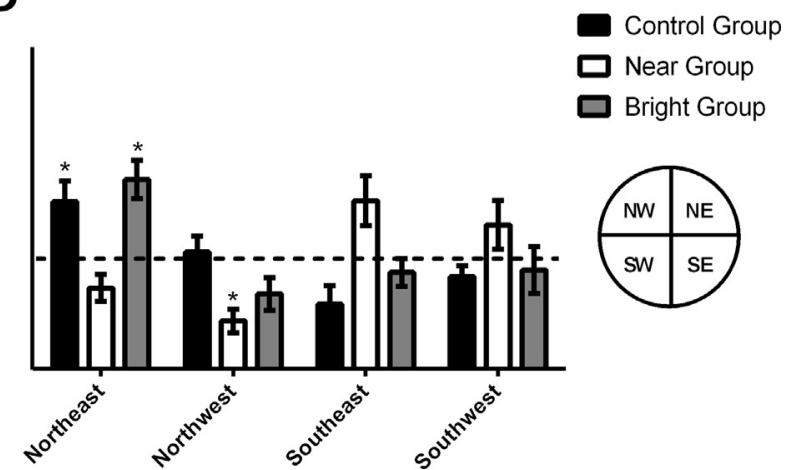

\begin{tabular}{|l|l|}
\hline$N W$ & $N E$ \\
\hline$S W$ & $S E$ \\
\hline
\end{tabular}

Quadrant

$\mathbf{F}$

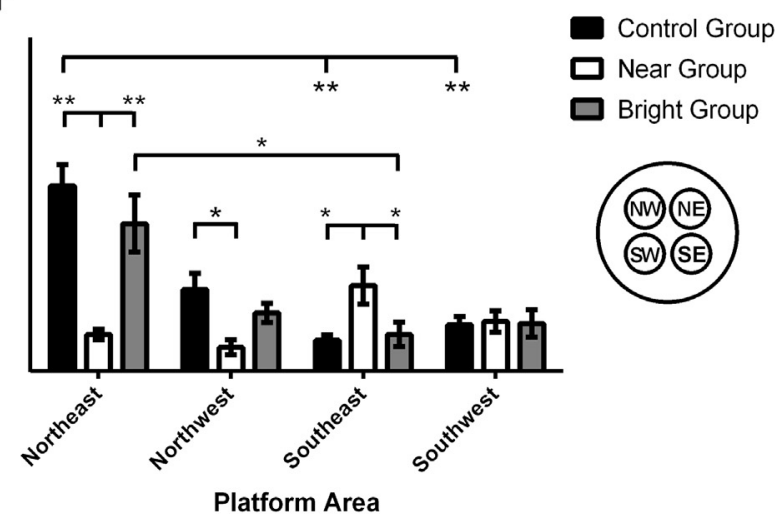

H

10 Day Training
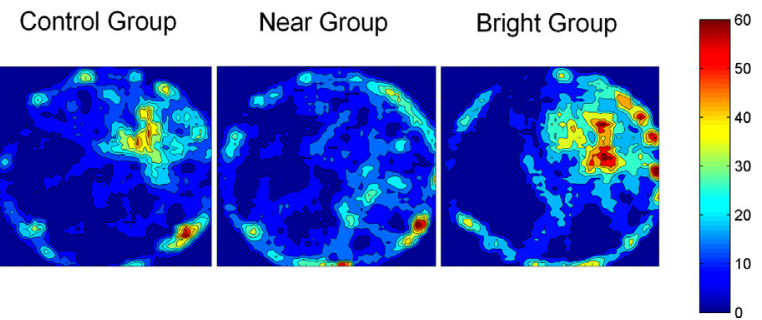

Fig. 2. (A-B) Mean escape latency for Control, Near and Bright groups trained for five and ten days. Open and closed circles represent $25 \mathrm{~W}$ and $40 \mathrm{~W}$ light bulbs, respectively. Closed circle inside maze indicates the platform location. (C-D) Mean percentage time spent by groups in the four quadrants compared to chance after five and ten day training. Dotted line indicates chance level (25\%). (E-F) Mean percentage time spent by groups in the four platform areas after five and ten day training. Error bars depict standard error of the mean (S.E.M.). ${ }^{*}=P<0.05,{ }^{* *}=P<0.01$, and ${ }^{* * *}=P<0.001$. (G-H) Heat maps showing search distributions during the probe trial according to group after five and ten days of training. 
to the other groups, the Near group spent significantly less time in the NE quadrant compared to chance, $t_{12}=6.79, P=0.001$ (see Fig. 2C). After ten days of training, Control and Bright groups continued to favour the target quadrant, $t_{10}=2.75, P<0.05$, and $t_{10}=4.57$, $P<0.05$, while the Near group spent significantly less time in the NW quadrant, $t_{10}=5.30, P=0.01$ (see Fig. 2D). No other significant deviations from chance level were found.

As a more specific indicator of rats' searching behaviour, percentage time spent in all four platform areas was assessed using a $3 \times 4$ mixed factorial ANOVA with group as the between-groups factor and platform area as the within-groups factor (NE, NW, SE and $\mathrm{SW}$ ). After five days of training, a significant main effect of area $\left(F_{3,54}=10.84, P=0.001\right.$, partial eta $\left.{ }^{2}=0.38\right)$ and area $\times$ group interaction effect $\left(F_{6,54}=3.60, P=0.02\right.$, partial eta $\left.{ }^{2}=0.29\right)$ were found. The main effect of group was not significant. Post hoc analyses showed that rats preferred the target platform area $(8.16 \pm 1.11 \mathrm{~s}, \mathrm{CI}[5.83$, $10.49])$ over the NW $(2.33 \pm 0.52 \mathrm{~s}, \mathrm{CI}[1.25,3.42] ; P=0.01)$ and SW areas $(3.41 \pm 0.46 \mathrm{~s}, \mathrm{CI}[2.44,4.39] ; P=0.04)$. When groups were examined separately using repeated measures ANOVAs, this preference was found to be driven by the Control group $\left(F_{3,18}=10.32\right.$, $P=0.01$, partial eta $\left.{ }^{2}=0.63\right)$ which spent more time in the target area compared to NW $(P=0.01)$ and SW areas $(P=0.04$; see Fig. $2 \mathrm{E}, \mathrm{G})$. The main effect of area was also significant for the Bright group $\left(F_{3,18}=8.79, P=0.02\right.$, partial eta $\left.{ }^{2}=0.59\right)$ but no post hoc differences were discovered. Subsequent Bonferroni corrected paired samples $t$-tests did, however, show that the Bright group spent significantly longer in the target area compared to the NW $\left(t_{6}=3.05, P=0.04\right)$ and SW areas $\left(t_{6}=3.09, P=0.04\right)$. The main effect of area for the Near group was not significant. To explore any group variations in time spent within an area, repeated measures ANOVAs were then conducted. A significant main effect of area was discovered in the target area only $\left(F_{2,20}=5.54, P=0.02\right)$, with the Bright group spending more time here than the Near group $(P=0.02)$.

Platform area analyses after ten day training produced comparable results. The main effect of area $\left(F_{3,45}=16.61, P=0.0001\right.$, partial eta $\left.^{2}=0.53\right)$ and area $\times$ group interaction effect were significant $\left(F_{6,45}=8.94, P=0.0001\right.$, partial eta $\left.{ }^{2}=0.54\right)$. The main effect of group was not significant. Bonferroni post hoc analysis showed that rats spent significantly longer in the target area $(10.48 \pm 1.01 \mathrm{~s}, \mathrm{CI}[8.32$, $12.64])$ compared to the three remaining areas (NW: $4.63 \pm 0.58 \mathrm{~s}$, CI [3.39, 5.87], SE: $4.33 \pm 0.64, \mathrm{CI}[2.97,5.70], \mathrm{SW}: 4.07 \pm 0.55 \mathrm{~s}, \mathrm{CI}$ $[2.91,5.24]$; all $P=0.01)$. Repeated measures ANOVAs indicated that this finding was mediated by the Control $\left(F_{3,15}=22.80, P=0.001\right.$, partial eta $\left.{ }^{2}=0.82\right)$ and Bright groups $\left(F_{3,15}=7.59, P=0.02\right.$, partial eta $\left.^{2}=0.60\right)$; where the Control group spent significantly more time in the NE area than in the southern areas (both $P=0.01$ ), and the Bright group spent more time in this area compared to the SE area $(P=0.04$; see Fig. $2 \mathrm{~F}, \mathrm{H})$. Again, between-groups ANOVAs were used to assess group differences within each area. Analyses yielded main effects for the NE $\left(F_{2,17}=14.04, P=0.0001\right)$, NW $\left(F_{2,17}=6.07\right.$, $P=0.02)$ and $S E$ areas $\left(F_{2,17}=5.31, P=0.02\right)$. Tukey post hoc comparisons showed that Control rats spent significantly longer in the NE and NW areas than the Near group $(P=0.01$ and $P=0.02)$, the Bright group also outperformed the Near group in the NE area $(P=0.01)$, while the Near group spent more time in the SE area compared to the other two groups $(P<0.03$ and $P=0.05)$.

\subsection{Discussion}

All groups acquired the task, as indicated by the decrease in time taken to escape the maze across five- and ten-day training periods. Furthermore, no group differences in escape latencies were found, signifying that groups showed equivalent learning. Analyses of time spent in quadrants and platform areas illustrated that, as expected, Control rats successfully navigated to the correct region of the maze using both cues, with an increase in searching specificity observed from five- to ten-day training. Animals tested with the bright cue also showed a steady preference for the target quadrant and area across training lengths, indicating that rats correctly assigned the available cue to their representation of the bright cue in memory. In contrast, the Near groups had poor overall retention, spending the majority of their time in the southern regions of the maze. The Near groups' tendency to search in the SE area after ten days could indicate that they misidentified the near cue as the bright cue, as searching in this region corresponds to the spatial relationship between the bright cue and the platform during training.

Taken together, results indicate that the cues did not acquire equal salience during training, but rather, the brighter distal cue rapidly became more salient than the proximal cue. This finding lends support to the idea that discrete features, in this case brightness, can influence the overall salience of a cue (Chamizo et al., 2006a,b,c; Young et al., 2006). With regard to strategy use, the divergent performance of the one-cue groups seems to suggest that animals employed an elemental strategy involving the bright cue to find the platform, similar to rats in Rodrigo et al. (2014). Importantly, no evidence for a shift in learning strategy was observed, as rats continued to rely on the bright cue even after extended training.

\section{Experiment 2}

The aim of Experiment 2 was to demonstrate that rats could learn to navigate using a bright cue in the near position, thereby controlling for cue location. Animals were trained for ten days with a bright, near cue and a far cue and tested with both or one cue. Since we expected the bright cue to acquire a higher salience than the near cue from the outset of learning (due to it being both brighter and closer to the platform), only one training length was employed.

\subsection{Method}

\subsubsection{Subjects and housing}

Twenty-one male Wistar rats obtained from Charles River, UK, were used as subjects (see Experiment 1 for details regarding age and weight). Rats were housed and maintained as per Experiment 1. All rats were habituated to handling for one week prior to the onset of training, as before.

\subsubsection{Morris water maze apparatus and procedure}

All apparatus and procedures were the same as in Experiment 1 with the exception that the location of the near and bright cues was reversed, such that the brighter cue was positioned closest to the platform (in the near position). All rats were trained for a total of ten days (four trials per day; 40 trials) in the presence of both cues, with probe trials being completed on day 11 . Prior to testing, rats were assigned to a Control group, tested with both cues (NE and NW), Bright group, tested with the bright (NE) cue, or Far group, tested with the far (NW) cue ( $n=7$ per group; see Fig. 1B, second row).

\subsection{Results}

\subsubsection{Acquisition}

Mean escape latencies were examined using a 3 (Control, Bright and Far groups) $\times 10$ (days 1-10) mixed factorial ANOVA with appropriate post hoc. In line with Experiment 1, a significant main effect of day was found $\left(F_{9,162}=29.20, P=0.0001\right.$, partial eta $\left.{ }^{2}=0.54\right)$. Post hoc tests showed that mean escape latency decreased from $39.46 \pm 2.91 \mathrm{~s}$ (CI $[33.33,45.56]$ ) on day 1 to $15.43 \pm 1.10 \mathrm{~s}$ (CI $[13.12,17.73])$ on day $10(P=0.001$; see Fig. $3 \mathrm{~A})$. The day $\times$ group interaction effect and main effect of group were not significant, and time taken to escape the maze did not differ 

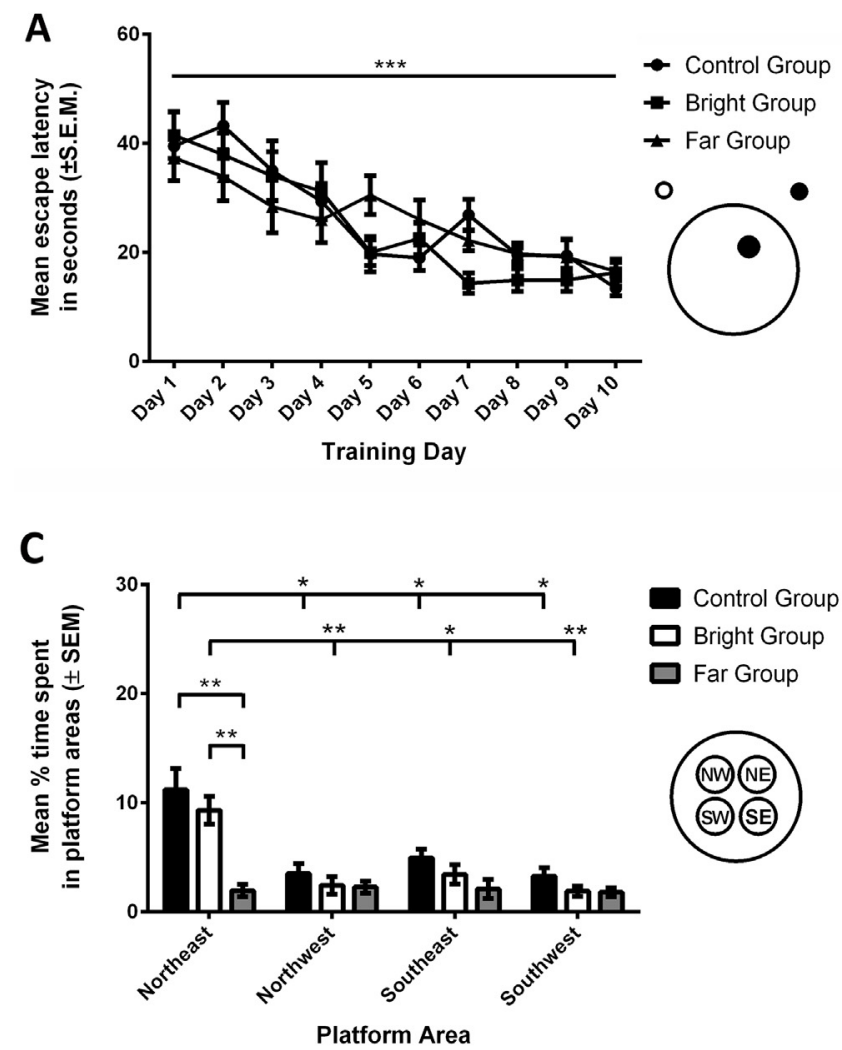

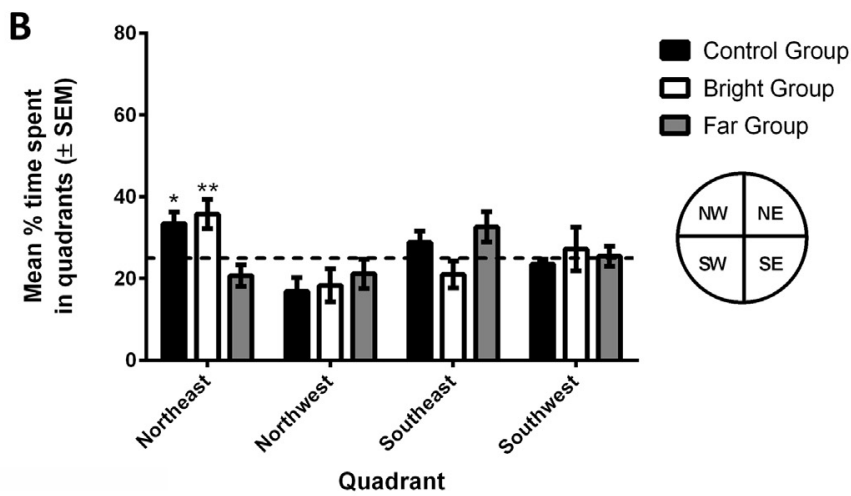

D

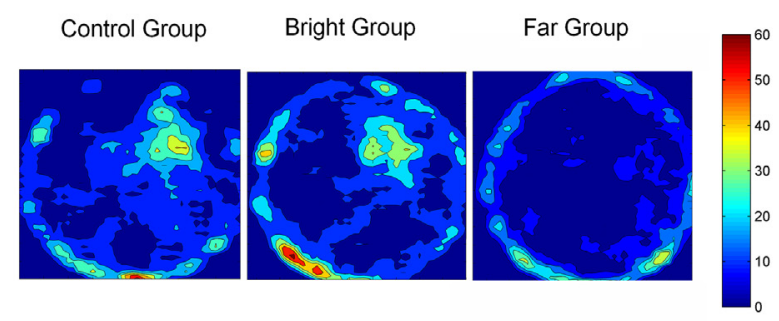

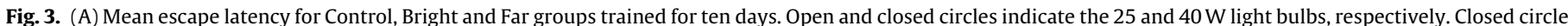

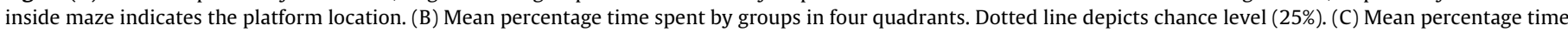

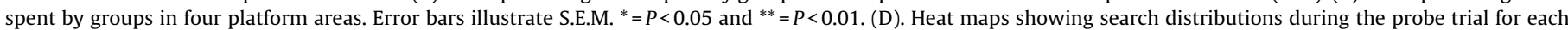
group after five- and ten-day training.

significantly across Control, Bright and Far groups on the final day of training.

\subsubsection{Retention}

During testing, time spent in the target quadrant was significantly above chance for the Control $\left(t_{12}=3.34, P=0.01\right)$ and Bright groups $\left(t_{12}=3.31, P=0.01\right)$, but not for the Far group (see Fig. $3 \mathrm{~B}$ ). No other significant differences were found for any other quadrant. Mixed factorial ANOVA assessing mean time spent in platform areas by groups yielded significant main effects for area $\left(F_{3,54}=18.75\right.$, $P=0.0001$, partial eta $\left.{ }^{2}=0.51\right)$ and group $\left(F_{1,18}=15.17, P=0.0001\right.$, partial eta ${ }^{2}=0.63$ ), as well as a significant area $\times$ group interaction effect $\left(F_{6,54}=4.89, P=0.01\right.$, partial eta $\left.{ }^{2}=0.31\right)$. Bonferroni post hoc tests revealed that rats spent more time in the NE area $(7.49 \pm 0.81 \mathrm{~s}$, $\mathrm{CI}[5.79,9.19])$ compared to the NW $(2.75 \pm 0.45 \mathrm{~s}, \mathrm{CI}[1.81,3.68])$, $\mathrm{SE}(3.49 \pm 0.49 \mathrm{~s}, \mathrm{CI}[2.47,4.52])$ and $\mathrm{SW}$ areas $(2.33 \pm 0.33, \mathrm{CI}[1.64$, 3.03]; all $P=0.001$ ). When time spent in areas was examined for each group individually, significant main effects of area were found for the Control group $\left(F_{3,18}=9.42, P=0.01\right.$, partial eta $\left.{ }^{2}=0.61\right)$ and the Bright group $\left(F_{3,18}=14.17, P=0.001\right.$, partial eta $\left.{ }^{2}=0.70\right)$, but not for the Far group (see Fig. 3C,D). Bonferroni corrected $t$-tests revealed that Control rats favoured the NE area over the NW $\left(t_{6}=3.39, P=0.045\right), \mathrm{SE}\left(t_{6}=3.31, P=0.048\right)$ and $\mathrm{SW}$ areas $\left(t_{6}=3.71\right.$, $P=0.03)$. Post hoc tests were significant for the Bright group, which preferred the target area over the NW $(P=0.05), \mathrm{SE}(P=0.01)$ and SW areas $(P=0.02)$. Similar to Experiment 1 , the Control and Bright groups spent a significantly greater length of time within the target area relative to the Far group $\left(F_{2,18}=12.19, P=0.0001\right.$; both $P=0.01$; see Fig. 3C). Group differences in all other areas were not significant.

\subsection{Discussion}

As per Experiment 1, all groups learned to escape the maze equally well after ten days of training. During the retention test the Control and Bright groups favoured the target quadrant and platform area, while rats navigating with the less luminous far cue were impaired. Results indicate that the bright cue again became the more salient of the two cues. Interestingly, the Far group did not appear to mistake the far cue for the bright cue here, as was noted in Experiment 1. Namely, this group showed no preference for searching in the NW region of the pool. It is possible that because the bright cue was both brighter and closer to the platform relative to the far cue, this cue acquired a beacon-like control over navigation (see Redhead et al., 1997), whereby animals paid little attention to the relationship between the far cue and the platform during training. Thus, rats were completely impaired with the near cue during retention. In line with Experiment 1, the discrepancy in performance level between the one-cue groups also implies the presence of an elemental over configural learning strategy.

\section{Experiment 3}

Findings from Experiments 1 and 2 showed that brightness can have a greater effect on cue salience than proximity to the goal. Therefore, the purpose of Experiment 3 was to more closely examine the role of proximity to the goal in determining cue salience, and consequently on the type of strategy learned. We also aimed to investigate if greater experience with a cue arrangement via increased training influenced the type of strategy used. Rats were trained with two cues of equal brightness positioned near to and 
far from the goal (as before) for five or ten days, followed by testing with two cues or a single cue.

\subsection{Method}

\subsubsection{Subjects and housing}

Thirty-eight male Wistar rats (3 months old, 250-300 g; Charles River, UK) were maintained, housed and handled as outlined in Experiment 1.

\subsubsection{Morris water maze apparatus and procedure}

Apparatus and procedures were identical to Experiment 1 with the exception of the far cue. For Experiment 3, the far cue was replaced with a $25 \mathrm{~W}$ light bulb, resulting in an environment with two equally bright distal cues. Rats were trained for five $(n=20 ; 20$ trials) or ten days in total ( $n=18 ; 40$ trials), followed 24 -h later by a single probe trial. Before testing, rats were randomly allocated to one of three groups; a Control group $(n=6)$, Near group or Far group (both $n=7$ ). Rats trained for ten days were grouped in the same way ( $n=6$ per group). Again, Control groups were tested with both cues (NE and NW), Near groups were tested with the near (NE) cue and Far groups with the far (NW) cue (see Fig. 1B, third row).

\subsection{Results}

\subsubsection{Acquisition}

Mixed factorial ANOVAs were once again employed to investigate time taken to escape the maze. Main effects of day were found after five $\left(F_{4,68}=33.86, P=0.0001\right.$, partial eta ${ }^{2}=0.67$; see Fig. $4 \mathrm{~A})$ and ten days of training $\left(F_{9,135}=25.88, P=0.0001\right.$, partial eta $^{2}=0.99$; see Fig. 4B). Day $\times$ group interaction effects and main effects of group were not significant for both training lengths. Bonferroni post hoc analyses indicated that escape latencies after five days $(11.97 \pm 1.35 \mathrm{~s}, \mathrm{CI}[9.12,14.82])$ and ten days $(10.39 \pm 0.92 \mathrm{~s}$, CI $[8.44,12.34])$ were significantly shorter compared to the initial training days $(31.23 \pm 1.68 \mathrm{~s}, \mathrm{CI}[27.68,34.79], P=0.001$, and $33.59 \pm 1.92 \mathrm{~s}, \mathrm{CI}[29.54,37.65], P=0.001)$. Groups did not differ significantly on the final day of training for either training length.

\subsubsection{Retention}

On completion of five days of training, no group displayed a significant preference for any quadrant (see Fig. 4C). The only significant finding was that the Far group spent significantly less time in the SW quadrant compared to chance level, $t_{12}=2.48, P=0.05$. After ten days of training time spent in the NE quadrant was significantly greater than chance for the Control group $\left(t_{10}=6.93\right.$, $P=0.001)$ and the Far group $\left(t_{10}=6.63, P=0.001\right)$, but not for the Near group (see Fig. 4D). Percentage times were significantly below chance level in the NW quadrant for the Near $\left(t_{10}=3.15, P=0.03\right)$ and Far groups $\left(t_{10}=4.43, P=0.01\right)$, and in the SW quadrant for the Control $\left(t_{10}=7.18, P=0.001\right)$ and Far groups $\left(t_{10}=3.89, P=0.02\right)$. A comparison of time spent in platform areas after five days of training produced a significant main effect of area $\left(F_{3,51}=3.13, P=0.03\right.$, partial eta $\left.{ }^{2}=0.16\right)$ and area $\times$ group interaction effect $\left(F_{6,51}=5.08\right.$, $P=0.0001$, partial eta ${ }^{2}=0.57$ ), but no main effect of group. Post hoc tests were not significant. Repeated measures ANOVAs showed that, of the three groups, Control rats spent significantly more time in the target area compared to NW and SE areas $\left(F_{3,15}=13.30\right.$, $P=0.001$, partial eta ${ }^{2}=0.73 ; P=0.01$, and $P=0.04$, respectively). Near and Far groups did not display a preference for any area (see Fig. 4E,G). The Control group also spent significantly longer in the NE area compared to the Near group, $F_{2,15}=13.30, P=0.02(P=0.02$; see Fig. 4E,G).

Analyses of groups trained for ten days produced a main effect of area $\left(F_{3,45}=48.33, P=0.001\right.$, partial eta $\left.{ }^{2}=0.76\right)$ and area $\times$ group interaction $\left(F_{6,45}=8.54, P=0.001\right.$, partial eta $\left.{ }^{2}=0.53\right)$. The main effect of group was not significant. Bonferroni post hoc comparisons showed that rats spent significantly more time in the target area $(9.57 \pm 0.77 \mathrm{~s}, \mathrm{CI}[7.93,11.22])$ compared to all other areas (NW: $2.04 \pm 0.43 \mathrm{~s}, \mathrm{CI}[1.13,2.94] ; \mathrm{SE}: 4.35 \pm 0.52 \mathrm{~s}$, CI [3.23, 5.47]; SW: $1.46 \pm 0.31, \mathrm{CI}[0.81,2.21]$; all $P=0.001)$. Individual main effects of area were also found for the Control $\left(F_{3,15}=34.82, P=0.001\right.$, partial eta $\left.{ }^{2}=0.87\right)$ and Far groups $\left(F_{3,15}=37.13, P=0.001\right.$, partial $\left.\mathrm{eta}^{2}=0.88\right)$. Both groups favoured the NE area over the NW $(P=0.02$ and $P=0.01)$, SE $(P=0.01$ and $P=0.02)$ and SW areas (both $P=0.01$ ) (see Fig. 4F,H). Furthermore, between-groups ANOVA showed that the Control and Far groups spent significantly longer in the NE area compared to the Near group, $F_{2,17}=11.84, P=0.01$ (both $P=0.01$; see Fig. $4 \mathrm{~F}$ ). Time spent in all other areas did not differ across groups.

\subsection{Discussion}

All groups successfully acquired the task after standard and extended training, as before. After five days of training, no strong group preferences were observed for any quadrant of the maze. However, the Control group did show an inclination to search in the NE area (over the NW and SE regions, and compared to the Near group). When the number of training trials was doubled, the performance of the Control and Far groups improved significantly. Both groups favoured the NE quadrant and the NE area over all remaining areas and relative to the Near group. In contrast, rats navigating with the proximal cue failed to search in the target regions after ten days. Not entirely unlike Experiment 1, the Near group did exhibit a slight tendency to search in eastern over western regions of the maze - although these differences did not reach significance. This preference could potentially denote that the cues were confounded, and thus rats, unsure of which cue was present, divided their time between searching in areas appropriate for each cue. Rats in the Far group showed no indication of a similar pattern of searching; time spent by this group in the NW quadrant was in fact significantly below chance level.

Overall, the results of Experiment 3 revealed that a distal cue can acquire greater salience than a proximal cue, contrary to our hypothesis and to some of the previous literature (Artigas et al., 2005; Chamizo and Rodrigo, 2004; Redhead and Hamilton, 2007). Furthermore, findings do not support our prediction regarding strategy use. The poor navigation of the one-cue groups after fiveday training indicates that rats did not adopt an elemental strategy from the beginning. Rather, it seems that animals initially engaged in configural learning with the entire cue arrangement, and only began to regard the farther cue as more salient after additional training. This could potentially have been due to the enhanced visual similarity of the cues (relative to Experiments 1 and 2) which may have promoted a configural learning approach, akin to the observations of Giurfa et al. (2003).

\section{General discussion}

The aim of this study was to examine the influence of cue salience and length of training on the type of spatial learning strategy used in the Morris water maze. Experiment 1 revealed that individual cue characteristics - in this case brightness - can become more salient, and thus acquire more control over animals' searching behaviour, than relative proximity to the goal. Experiment 2 showed that reliance on the more salient (brighter) cue can be increased if this cue is also closer to the goal. This finding supports the idea that multiple components of cue salience can have an additive effect on behaviour (Bennett, 1996; Chamizo et al., 2006b). Together, results suggest that the presence of a brighter cue may have interfered with the amount of spatial information rats' learned about the alternate cue throughout training 
A

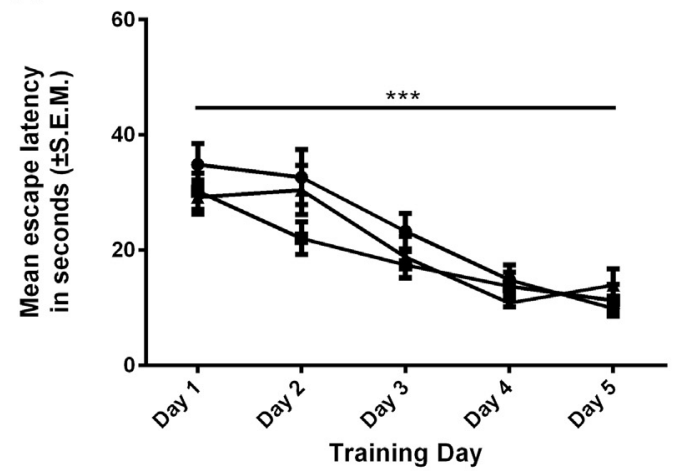

C

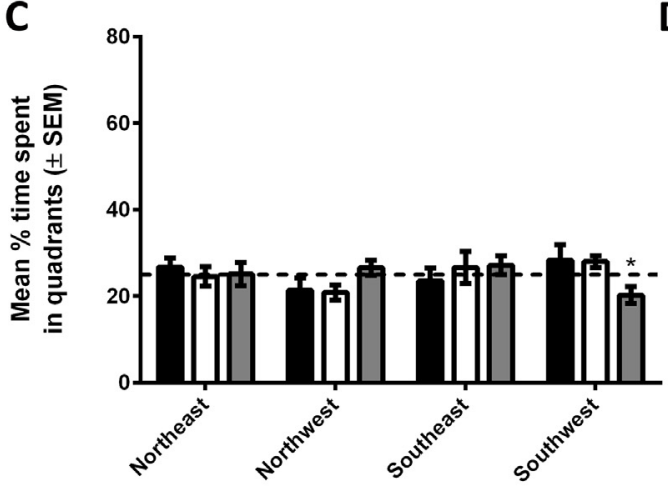

Quadrant

E

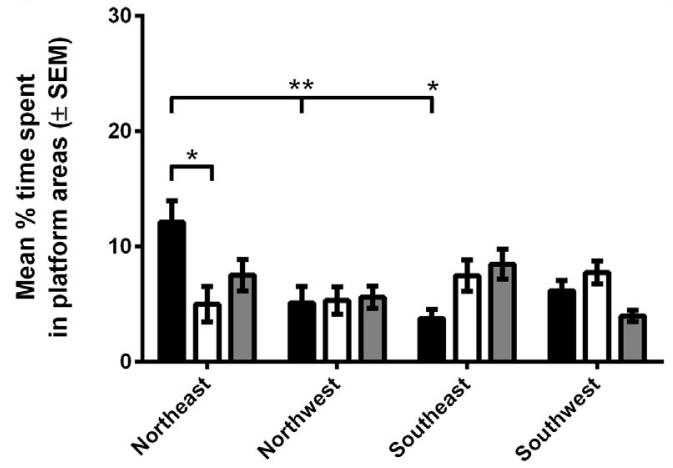

Platform Area
B 10 Day Training

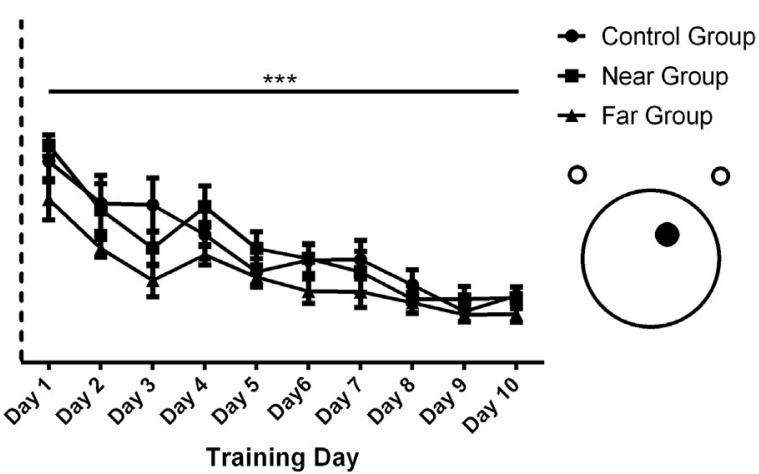

D

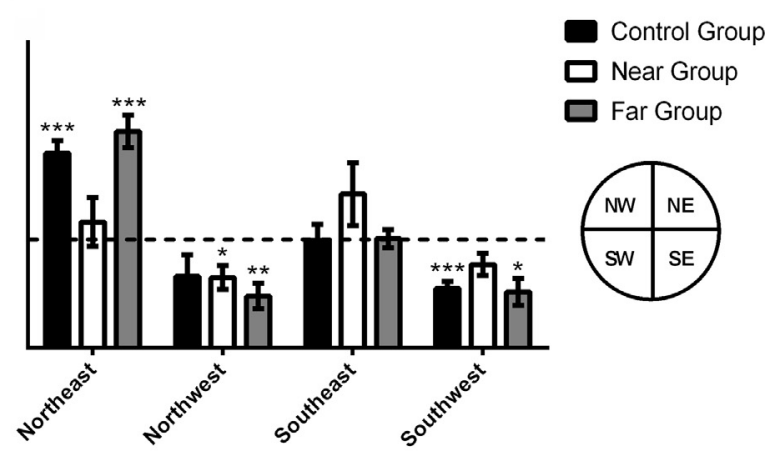

Quadrant

$\mathbf{F}$

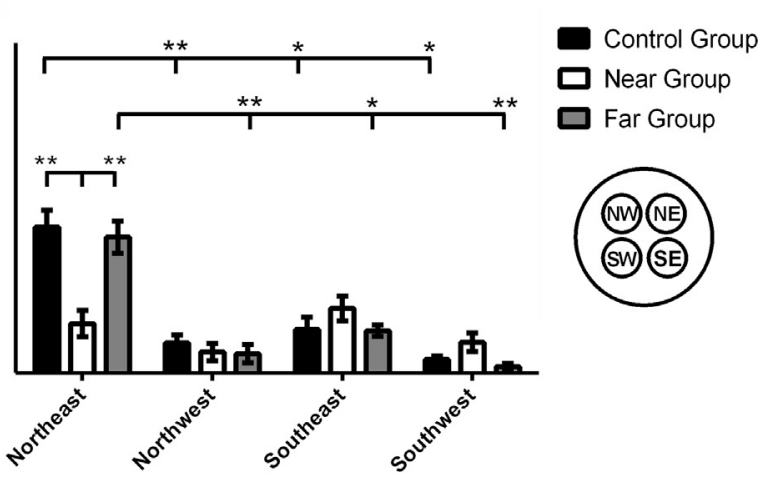

Platform Area
G 5 Day Training

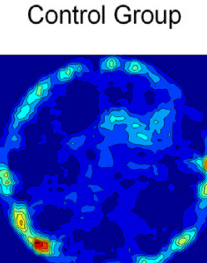

Near Group

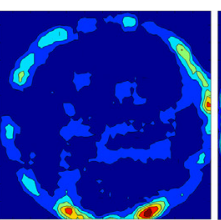

Far Group

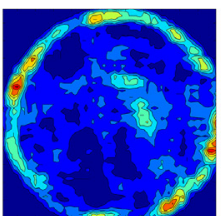

H

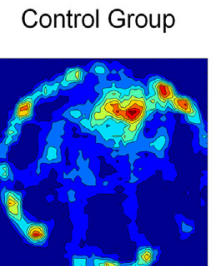

10 Day Training

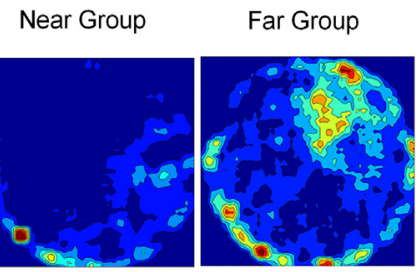

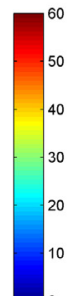

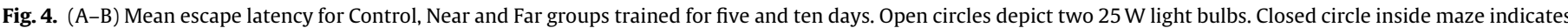

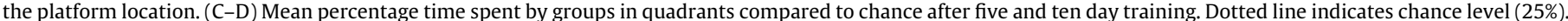

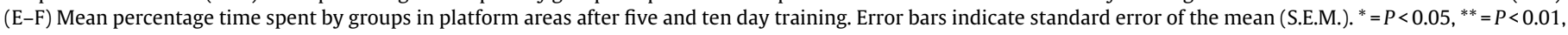
and $^{* * *}=P<0.001$. $(\mathrm{G}-\mathrm{H})$ Heat maps illustrating search distributions during the probe trial according to group after five and ten days of training. 
(near cue in Experiment 1 and far cue in Experiment 2), i.e. an interference by salience effect (Crespo et al., 2012; Rodrigo et al., 2014). Furthermore, we observed that greater disparity between the salience of cues can lead to more interference. More specifically, rats navigating with a dim near cue misdirected their searching to regions appropriate for the bright cue (Experiment 1), whereas those navigating with a cue that was both dimmer and farther from the platform appeared to be completely impaired (Experiment 2). This disproportionate reliance on one cue relative to the other is indicative of an elemental strategy which was acquired quickly, i.e. after only twenty training trials in Experiment 1; less than half of the number administered by Rodrigo et al. (2014).

When brightness was removed as a component of cue salience in Experiment 3, a different pattern of results emerged. Rats trained with two equally bright cues for five days failed to find the correct platform location using either cue in isolation, whereas after forty training trials, rats navigating with the far cue (in addition to Controls) displayed good retention. The perceived change in navigational ability suggests that the cues initially acquired similar saliences, but that the far cue became more salient than the near cue over time. This points towards the use of a configural strategy with the intact cue arrangement at first, followed by a shift towards elemental processing involving the far cue. Here, the interference by salience effect appears to have been dependant on additional training (Crespo et al., 2012; Rodrigo et al., 2014). As mentioned, the delayed emergence of an elemental strategy in Experiment 3 compared with Experiments 1 and 2 could be due to the fact that cues were visually indistinguishable in this experiment. It is probable that the enhanced perceptual similarity of the cues made it difficult for rats to differentiate between them during the early stages of training, causing them to rely on both cues to orient towards the platform. This result is in line with Rodrigo et al. (2014), who showed that rats trained in the water maze with two cues of equivalent saliences navigated via a configural strategy.

Unexpectedly, the far cue acquired greater behavioural control after extended training, despite offering no obvious advantage over the near cue. One simple explanation for this is that rats made use of incidental room cues unknown to the experimenter. Indeed, it is difficult to determine the features of an environment that will be considered most salient to a rat (Young et al., 2006). However, unintentional visual cues were obscured from view by the addition of the surrounding curtain and by the administration of all training and testing in complete darkness. Further, it is doubtful that animals were relying on static auditory or olfactory cues (e.g. air conditioning) as, if this were the case, we would have expected groups to navigate equally well regardless of which cue was removed. One further straightforward suggestion is that rats were using an inertial sense of direction via their vestibular system to guide navigation, as previously shown by Cheng (1986). However, the use of multiple rotations during training as well as novel start positions during retention makes this, or the use of habitual or procedural responding (Packard and McGaugh, 1992), an unlikely explanation.

Nevertheless, rats evidently learned to distinguish between the cues on some non-salient physical feature, which resulted in the far cue acquiring more salience. We propose that rats discriminated between the cues based on their spatial position relative to the platform. Furthermore, we suggest that the positioning of the distal cue allowed for a more reliable estimation of the platform location than the proximal cue, causing the former to become more salient. Research has shown that errors in estimating distance tend to increase more rapidly than directional errors as a cue gets farther from the goal (Kamil and Cheng, 2001; Kamil and Jones, 1997, 2000). Therefore, we can reasonably assume that the far cue in the current study was a better indicator of directional (as opposed to distance) information. Previous work with rats in the water maze has also demonstrated that a loss of directional information affects performance more negatively than a comparable loss of distance information, suggesting that the former is weighted more heavily (Diviney et al., 2013; see Kamil and Jones, 2000 for a similar suggestion in birds).

In addition, research in desert ants has highlighted the importance of cue elevation for navigation, whereby cues of a lower elevation allow for a more precise estimation of direction (Müller and Wehner, 2007). Crucially, the elevation of the farther cue (positioned $162 \mathrm{~cm}$ from the platform) was lower than that of the closer cue $(127 \mathrm{~cm}$ from the platform) in the present study. Moreover, the elevation of the near cue would have increased as animals approached and mounted the platform (making it more difficult to gauge directional information), whereas the elevation of the far cue would have remained fairly stable. Therefore, taking the elevations of the cues into account, in combination with the importance of directional information, it seems reasonable that rats would regard the distal cue as more useful; however, future work exploring cue elevations systematically in the water maze is needed to confirm this suggestion.

If rats had established the far cue as a primary source of directional information, the question of how they navigated without a second cue to provide distance information still remains. As previously stated, a single cue cannot unambiguously define the location of a goal (Harvey et al., 2009). To account for this, we suggest that the perimeter of the maze played an important role in the estimation of distance, and ultimately in establishing the far cue's higher salience. The use of the pool wall as an aid in locating the platform is well-documented (Austen et al., 2013; Hamilton et al., 2007; Harvey et al., 2009). Specifically, rats have been shown to swim in circles around the maze at a set distance from the pool wall in search of the platform, indicating that they can easily estimate distance information from the wall (Alvarado and Rudy, 1995; see Artigas et al., 2005, for a similar finding with humans in a virtual water maze; Chamizo et al., 2006a; Maurer and Derivaz, 2000). Importantly, animals would be unable to obtain directional information from the shape of the maze in the current set of experiments, as has been illustrated previously (see Pearce, 2009), due to its circular shape. We posit that in our study, the near cue could have been replaced by the pool wall relatively easily as a result of its position close to and in the same quadrant as the platform.

Although our results are indicative of an elemental learning involving the more salient of two cues, we cannot definitively rule out the use of a configural strategy. As Rodrigo et al. (2014) state, the separation of elemental and configural learning strategies is not easily achievable. According to configural accounts, elemental representations are retained in memory, although they do not become directly associated with the goal (Pearce, 1987, 1994). Thus, once established, a configural representation can be proportionately activated by any of its original elements (Pearce, 1994; Rodrigo et al., 2014; Sutherland and Rudy, 1989). As such, it is possible that rats in our study established a configural representation with both cues (and pool wall) which was then generated during testing with a single cue (Rodrigo et al., 2014). However, if this were the case, we would have expected animals to find the correct platform location using either cue in isolation, i.e. with the near cue in Experiments 1 and 3 and the far cue in Experiment 2. More specifically, the remaining cue should have triggered a representation of the overall configuration including the absent cue, allowing rats to navigate accurately (Rodrigo et al., 2014). One future experiment that could potentially elucidate use of one strategy over another is to examine the effects of varying cue salience on tasks involving configural discrimination, e.g. negative patterning (similar to Bussey et al., 2000; who investigated the effects of lesions on negative patterning). 
In sum, findings from the current study lend support to the idea of an enhanced flexibility of spatial behaviour (Sturz and Katz, 2009). Rather than being mutually exclusive, it seems more likely that searching behaviour can come under the control of whichever strategy (elemental or configural) is most beneficial for navigating a particular environment (Biegler and Morris, 1999; Kamil and Jones, 1997, 2000; Rodrigo et al., 2014). Our results provide novel evidence that the utility of a strategy is at least partially determined by the relative saliences of the cues and the length of training. When one cue is notably more salient than the other, rats quickly learn to rely on the spatial information offered by this cue instead of the entire arrangement, which may be suggestive of a learning efficiency. Furthermore, rats' ability to navigate using this strategy develops more slowly when the available cues are of similar saliences.

\section{Acknowledgements}

The authors thank D.N. Barry and M. Diviney for assistance during data collection. This research was supported by the Maynooth University Doctoral Teaching Scholarship awarded to F. R. Farina.

\section{References}

Alvarado, M.C., Rudy, J.W., 1995. Rats with damage to the hippocampal-formation are impaired on the transverse-patterning problem but not on elemental discriminations. Behav. Neurosci. 109 (2), 204-211.

Artigas, A.A., Aznar-Casanova, J.A., Chamizo, V.D., 2005. Effects of absolute proximity between landmark and platform in a virtual Morris pool task with humans. Int. J. Comp. Psychol. 18 (3), 225-239.

Austen, J.M., Kosaki, Y., McGregor, A., 2013. Within-compound associations explain potentiation and failure to overshadow learning based on geometry by discrete landmarks. J. Exp. Psychol. Anim. Behav. Process 39 (3), 259-272, http://dx.doi.org/10.1037/a0032525.

Bennett, A.T., 1996. Do animals have cognitive maps? J. Exp. Biol. 199 (Pt 1), 219-224.

Biegler, R., Morris, R.G., 1999. Blocking in the spatial domain with arrays of discrete landmarks. J. Exp. Psychol. Anim. Behav. Process 25 (3), 334-351.

Bussey, T.J., Dias, R., Redhead, E.S., Pearce, J.M., Muir, J.L., Aggleton, J.P., 2000. Intact negative patterning in rats with fornix or combined perirhinal and postrhinal cortex lesions. Exp. Brain Res. 134 (4), 506-519.

Cartwright, B., Collett, T., 1982. How honey bees use landmarks to guide their return to a food source. Nature 295, 560-564.

Chamizo, V.D., 2002. Spatial learning conditions and basic effects. Psicol.: Rev. Metod. Psicolo. Exp. 1, 33-58.

Chamizo, V.D., Manteiga, R.D., Rodrigo, T., Mackintosh, N.J., 2006a. Competition between landmarks in spatial learning: the role of proximity to the goal. Behav. Process. 71 (1), 59-65, http://dx.doi.org/10.1016/j.beproc.2005.11.003.

Chamizo, V.D., Rodrigo, T., 2004. Effect of absolute spatial proximity between a landmark and a goal. Learn. Motiv. 35 (2), 102-114 http://dx.doi.org/10.1016/S0023-9690(03)59-6

Chamizo, V.D., Rodrigo, T., Mackintosh, N.J., 2006b. Spatial integration with rats. Learn. Behav. 34 (4), 348-354.

Chamizo, V.D., Rodrigo, T., Peris, J.M., Grau, M., 2006c. The influence of landmark salience in a navigation task: an additive effect between its components. J. Exp. Psychol. Anim. Behav. Process 32 (3), 339-344, http://dx.doi.org/10.1037/0097-7403.32.3.339.

Chamizo, V.D., Rodriguez, C.A., Espinet, A., Mackintosh, N.J., 2012. Generalization decrement and not overshadowing by associative competition among pairs of landmarks in a navigation task. J. Exp. Psychol. Anim. Behav. Process. 38 (3) 255-265, http://dx.doi.org/10.1037/a0029015.

Cheng, K., 1986. A purely geometric module in the rat's spatial representation. Cognition 23 (2), 149-178.

Cheng, K., Collett, T.S., Pickhard, A., Wehner, R., 1987. The use of visual landmarks by honeybees: Bees weight landmarks according to their distance from the goal. J. Comp. Physiol. [A] 161 (3), 469-475, http://dx.doi.org/10.1007/BF00603972.

Collett, T., Cartwright, B., Smith, B., 1986. Landmark learning and visuo-spatial memories in gerbils. J. Comp. Physiol. [A] 158 (6), 835-851.

Crespo, P., Rodriguez, C.A., Chamizo, V.D., 2012. Learning in a navigation task: the role of salience of pairs of landmarks and sex differences. Anuario Psicología 42 (3), 361-376.

Diviney, M., Fey, D., Commins, S., 2013. Hippocampal contribution to vector model hypothesis during cue-dependent navigation. Learn. Mem. 20 (7), 367-378, http://dx.doi.org/10.1101/lm.029272.112.

Domjan, M., Grau, J.W., Krause, M.A., 2010. The Principles of Learning and Behavior, 6th ed. Wadsworth Cenage Learning, Australia; Belmont, CA.
Giurfa, M., Schubert, M., Reisenman, C., Gerber, B., Lachnit, H., 2003. The effect of cumulative experience on the use of elemental and configural visual discrimination strategies in honeybees. Behav. Brain Res. 145 (1-2), $161-169$.

Hamilton, D.A., Akers, K.G., Weisend, M.P., Sutherland, R.J., 2007. How do room and apparatus cues control navigation in the Morris water task? Evidence for distinct contributions to a movement vector. J. Exp. Psychol. Anim. Behav. Process 33 (2), 100-114, http://dx.doi.org/10.1037/0097-7403.33.2.100.

Hamilton, D.A., Driscoll, I., Sutherland, R.J., 2002. Human place learning in a virtual Morris water task: some important constraints on the flexibility of place navigation. Behav. Brain Res. 129 (1-2), 159-170.

Harvey, D.R., Brant, L., Commins, S., 2009. Differences in cue-dependent spatial navigation may be revealed by in-depth swimming analysis. Behav. Process. 82 (2), 190-197, http://dx.doi.org/10.1016/j.beproc.2009.06.008.

Honey, R.C., Iordanova, M.D., Good, M., 2014. Associative structures in animal learning: Dissociating elemental and configural processes. Neurobiol. Learn. Mem. 108 (0), 96-103 http://dx.doi.org/10.1016/j.nlm.2013.06.002

Hoz, L.D., Martin, S.J., Morris, R.G.M., 2004. Forgetting, reminding, and remembering: the retrieval of lost spatial memory. PLoS Biol. 2 (8), e225 http://dx.doi.org/10.1371/journal.pbio.0020225.

Kamil, A.C., Cheng, K., 2001. Way-finding and landmarks: the multiple-bearings hypothesis. J. Exp. Biol. 204 (Pt 1), 103-113.

Kamil, A.C., Jones, J.E., 1997. The seed-storing corvid Clark's nutcracker learns geometric relationships among landmarks. Nature 390 (6657), 276-279.

Kamil, A.C., Jones, J.E., 2000. Geometric rule learning by Clark's nutcrackers (Nucifraga columbiana). J. Exp. Psychol. Anim. Behav. Process 26 (4), 439-453.

Leonard, B., McNaughton, B., 1990. Spatial representation in the rat: conceptual, behavioral, and neurophysiological perspectives. Neurobiol. Comp. Cogn., 363-422.

MacDonald, S.E., Spetch, M.L., Kelly, D.M., Cheng, K., 2004. Strategies in landmark use by children, adults, and marmoset monkeys. Learn. Motiv. 35 (4), 322-347.

Maurer, R., Derivaz, V., 2000. Rats in a transparent morris water maze use elemental and configural geometry of landmarks as well as distance to the pool wall. Spat. Cogn. Comput. 2 (2), 135-156, http://dx.doi.org/10.1023/A.1011477931753.

Miller, N.Y., Shettleworth, S.J., 2007. Learning about environmental geometry: an associative model. J. Exp. Psychol. Anim. Behav. Process 33 (3) 191-212, http://dx.doi.org/10.1037/0097-7403.33.3.191.

Morris, R.G., 1981. Spatial localization does not require the presence of local cues. Learn. Motiv. 81, 239-260 http://dx.doi.org/10.1016/0023-9690(81)90020-5

Müller, M., Wehner, R., 2007. Wind and sky as compass cues in desert ant navigation. Naturwissenschaften 94 (7), 589-594.

Packard, M.G., McGaugh, J.L., 1992. Double dissociation of fornix and caudate nucleus lesions on acquisition of two water maze tasks: further evidence for multiple memory systems. Behav. Neurosci. 106 (3), 439-446.

Pearce, J.M., 1987. A model for stimulus generalization in Pavlovian conditioning Psychol. Rev. 94 (1), 61-73.

Pearce, J.M., 1994. Similarity and discrimination: a selective review and a connectionist model. Psychol. Rev. 101 (4), 587-607.

Pearce, J.M., 2002. Evaluation and development of a connectionist theory of configural learning. Anim. Learn. Behav. 30 (2), 73-95.

Pearce, J.M., 2009. The 36th Sir Frederick Bartlett lecture: an associative analysis of spatial learning. Q. J. Exp. Psychol. (Hove) 62 (9), 1665-1684, http://dx.doi.org/10.1080/17470210902805589.

Redhead, E.S., Hamilton, D.A., 2007. Interaction between locale and taxon strategies in human spatial learning. Learn. Motiv. 38 (3), 262-283 http://dx.doi.org/10.1016/j.lmot.2006.11.003

Redhead, E.S., Roberts, A., Good, M., Pearce, J.M., 1997. Interaction between piloting and beacon homing by rats in a swimming pool. J. Exp. Psychol. Anim. Behav. Process 23 (3), 340-350.

Rescorla, R.A., Durlach, P.J., Grau, J.W., 1985. Contextual learning in Pavlovian conditioning. Context Learn., 23-56.

Rescorla, R.A., Wagner, A.R. 1972. A theory of pavlovian conditioning: variations in the effectiveness of reinforcement and nonreinforcement, Classical conditioning: current research and theory.

Rodrigo, T., 2002. Navigational strategies and models. Psicol.: Rev. Metod. Psicol. Exp. 23 (1), 3-32.

Rodrigo, T., Gimeno, E., Ayguasanosa, M., Chamizo, V.D., 2014. Navigation with two landmarks in rats (Rattus norvegicus): the role of landmark salience. J. Comp. Psychol. 128 (4), 378-386, http://dx.doi.org/10.1037/a0036544.

Rudy, J.W., Sutherland, R.J., 1995. Configural association theory and the hippocampal formation: an appraisal and reconfiguration. Hippocampus 5 (5), 375-389, http://dx.doi.org/10.1002/hipo.450050502.

Siegel, A.W., White, S.H., 1975. The development of spatial representations of large-scale environments. Adv. Child Dev. Behav. 10, 9

Spetch, M.L., 1995. Overshadowing in landmark learning: touch-screen studies with pigeons and humans. J. Exp. Psychol. Anim. Behav. Process 21 (2), 166-181.

Spetch, M.L., Cheng, K., MacDonald, S.E., 1996. Learning the configuration of a landmark array: I. Touch-screen studies with pigeons and humans. J. Comp. Psychol. 110 (1), 55.

Spetch, M.L., Cheng, K., MacDonald, S.E., Linkenhoker, B.A., Kelly, D.M., Doerkson, S.R., 1997. Use of landmark configuration in pigeons and humans: II. Generality across search tasks. J. Comp. Psychol. 111 (1), 14. 
Spetch, M.L., Wilkie, D.M., 1994. Pigeons' use of landmarks presented in digitized images. Learn. Motiv. 25 (3), 245-275 http://dx.doi.org/10.1006/lmot.1994.1014

Sturz, B.R., Katz, J.S., 2009. Learning of absolute and relative distance and direction from discrete visual landmarks by pigeons (Columba livia). J. Comp. Psychol. 123 (1), 90-113, http://dx.doi.org/10.1037/a0012905.

Sutherland, R.J., Rudy, J.W., 1989. Configural association theory: the role of the hippocampal formation in learning, memory, and amnesia. Psychobiology 17 (2), 129-144, doi: citeulike-article-id:5013782
Tommasi, L., Chiandetti, C., Pecchia, T., Sovrano, V.A., Vallortigara, G., 2012. From natural geometry to spatial cognition. Neurosci. Biobehav. Rev. 36 (2), 799-824, http://dx.doi.org/10.1016/j.neubiorev.2011.12.007.

Young, G.S., Choleris, E., Kirkland, J.B., 2006. Use of salient and non-salient visuospatial cues by rats in the Morris water maze. Physiol. Behav. 87 (4), 794-799 http://dx.doi.org/10.1016/j.physbeh.2006.01.022 